\title{
An age-based analysis of nonmedical prescription opioid use among people who use illegal drugs in Vancouver, Canada
}

\author{
Tessa Cheng ${ }^{1,2}$, Will Small ${ }^{1,2,4}$, Huiru Dong ${ }^{2,3}$, Ekaterina Nosova ${ }^{2}$, Kanna Hayashi ${ }^{1,2}$ and Kora DeBeck ${ }^{2,5^{*}}$ (D)
}

\begin{abstract}
Background: Nonmedical prescription opioid use (NMPOU) is a serious public health problem in North America. At a population-level, previous research has identified differences in the prevalence and correlates of NMPOU among younger versus older age groups; however, less is known about age-related differences in NMPOU among people who use illegal drugs.
\end{abstract}

Methods: Data were collected between 2013 and 2015 from two linked prospective cohort studies in Vancouver, Canada: the At-Risk Youth Study (ARYS) and the Vancouver Injection Drug Users Study (VIDUS). Factors independently associated with NMPOU among younger (ARYS) and older (VIDUS) participants were examined separately using bivariate and multivariate generalized estimating equations.

Results: A total of 1162 participants were included. Among 405 eligible younger participants (Median age = 25; Inter-Quartile Range [IQR]: 22-28), 40\% ( $n=160)$ reported engaging in NMPOU at baseline; among 757 older participants (Median age $=48$, IQR: 40-55), 35\% $(n=262)$ reported engaging in NMPOU at baseline. In separate multivariate analyses of younger and older participants, NMPOU was positively and independently associated with heroin use (younger: Adjusted Odds Ratio [AOR] = 3.12, 95\% Confidence Interval [Cl]: 2.08-4.68; older: AOR = 2.79, 95\% Cl: 2.08-3.74), drug dealing (younger: $A O R=2.22,95 \%$ Cl: 1.58-3.13; older: $A O R=1.87,95 \%$ Cl: 1.40-2.49), and difficulty accessing services (younger: $\mathrm{AOR}=1.47,95 \% \mathrm{Cl}: 1.04-2.09$; older: $\mathrm{AOR}=1.74,95 \% \mathrm{Cl}: 1.32-2.29$ ). Among the youth cohort only, NMPOU was associated with younger age (AOR =1.12, 95\% Cl: 1.05-1.19), crack use (AOR=1.56, 95\% Cl: 1. 06-2.30), and binge drug use (AOR $=1.41,95 \% \mathrm{Cl}: 1.00-1.97)$; older participants who engaged in NMPOU were more likely to report crystal methamphetamine use ( $\mathrm{AOR}=1.97,95 \% \mathrm{Cl}: 1.46-2.66)$, non-fatal overdose (AOR =1.76, 95\% Cl: 1. 20-2.60) and sex work (AOR $=1.49,95 \% \mathrm{Cl}: 1.00-2.22)$.

Discussion: The prevalence of NMPOU is similar among younger and older people who use drugs, and independently associated with markers of vulnerability among both age groups. Adults who engage in NMPOU are at risk for non-fatal overdose, which highlights the need for youth and adult-specific strategies to address NMPOU that include better access to health and social services, as well as a range of addiction treatment options for opioid use. Findings also underscore the importance of improving pain treatment strategies tailored for PWUD.

Keywords: Prescription opioids, Risk behavior, Addictions, Youth, Overdose

\footnotetext{
* Correspondence: bccsu-kd@bccsu.ubc.ca

${ }^{2}$ British Columbia Centre on Substance Use, Providence Health Care,

400-1045 Howe St, Vancouver, BC V6Z 2A9, Canada

${ }^{5}$ School of Public Policy, Simon Fraser University, 515 West Hastings Street,

Suite 3271, Vancouver, BC V6B 5K3, Canada

Full list of author information is available at the end of the article
}

(c) The Author(s). 2018 Open Access This article is distributed under the terms of the Creative Commons Attribution 4.0 International License (http://creativecommons.org/licenses/by/4.0/), which permits unrestricted use, distribution, and reproduction in any medium, provided you give appropriate credit to the original author(s) and the source, provide a link to the Creative Commons license, and indicate if changes were made. The Creative Commons Public Domain Dedication waiver (http://creativecommons.org/publicdomain/zero/1.0/) applies to the data made available in this article, unless otherwise stated. 


\section{Background}

Rates of medical and nonmedical prescription opioid use (NMPOU) are rising across Canada and the United States [1], along with shifts towards increases in the global consumption of opioids [2]. Research consistently indicates that adolescents and young adults are more likely to engage in NMPOU than older youth and adults [3-11], and evidence suggests that these differences in prescription opioid (PO) use are associated with statistically significant birth cohort effects; more recent birth cohorts have higher lifetime and past-year prevalence of prescription opioid -use disorder due to NMPOU [12]. Adolescents and young adults in the United States are more likely to initiate NMPOU than older age groups [3,13-15], and a study of the American general population found that the most frequently reported age of NMPOU initiation was 16-18 years [16]. This effect has been attributed to the increased availability of POs [4], and other research among street-involved youth has found that the easy availability of POs facilitates NMPOU [17]. In addition, those who engage in NMPOU are more likely to be younger than those engaging in other illegal drug use [18], and adolescents and young adults are also more likely to share and receive any class of prescription medications, including POs, than older age groups [19]. For the purposes of this study, "youth", "young adult", and "younger age groups" are used to describe individuals in their late teens and up to the late 20's [20]. "Adult" and "older age groups" include those over the age of majority but focuses on those in their mid-life and older.

Youth-specific strategies to address substance use are often prioritized due to the developmental harms associated with licit and illegal substances [21]; however, the prevalence of NMPOU among adults up to age 64 is significantly higher than among adults over the age of 65 [22], and the ubiquity of PO use has resulted in a significant risk of engaging in NMPOU that increases with age [12]. The increase in PO use among older individuals is especially problematic given that age-related physiological changes (e.g., drug absorption) increase the harms of $\mathrm{PO}$ use among older adults, such as hyperalgesia [23]. Research has also identified a key difference related to NMPOU among younger and older age groups, where pain is a more frequent motivator for engaging in NMPOU among adults [24] and youth are more likely to engage in NMPOU for its euphoric effects [6].

Although younger and older age groups are both at risk for engaging in NMPOU, the majority of research findings related to NMPOU rely on population-level sampling and national surveys that often exclude marginalized groups who are unstably housed or have low incomes. Despite previous research investigating NMPOU among people who use illegal drugs (PWUD) in Canadian and American settings [17, 25-34], there have been few if any studies characterizing age-based differences associated with NMPOU among PWUD. Given that this population already experiences numerous risks and harms related to substance use [35], this study investigates age-based differences associated with NMPOU among younger and older PWUD in Vancouver.

\section{Methods}

Data from this study were drawn from two prospective open cohort studies: the At-Risk Youth Study (ARYS) and the Vancouver Injection Drug Users Study (VIDUS). ARYS and VIDUS use a harmonized study questionnaire and study participants can attend a study visit at either study office regardless of their cohort enrollment. ARYS and VIDUS have both been described in detail previously [36, 37]. VIDUS is a cohort of HIV-negative adult PWUD who injected illegal drugs at least once in the month prior to enrolment. Participants in the VIDUS cohort are recruited through self-referral and street outreach, which has been ongoing since 1996. In brief, ARYS has been operating since 2005 as a cohort study of street-involved youth. To be eligible, participants must be aged 14-26 years at recruitment and also have used illegal drugs other than cannabis in the past 30 days, provide written informed consent, and be "street-involved". In this cohort, "street-involved" is defined as being absolutely, periodically, or temporarily homeless (e.g., having no fixed address, sleeping on the street, couch surfing, or staying in a shelter or hostel), and includes those who are not homeless but have used services designated for street-youth (e.g., youth-specific drop-in centres, social services, and harm reduction services) in the last year. Youths' street involvement and eligibility to participate are assessed during a semi-structured in-person interview with an ARYS staff member.

At enrolment, and on a semi-annual basis, participants in ARYS and VIDUS complete a questionnaire that is administered by trained study staff. The questionnaire includes questions related to demographic information and drug use patterns. At each study visit, participants are provided with a stipend $(\$ 30 \mathrm{CDN})$ for their time. The ARYS and VIDUS studies have been approved by the University of British Columbia/Providence Health Care Research Ethics Board.

All ARYS and VIDUS participants who completed a study visit between December 2013 and May 2015 were eligible for the present analyses, as PO-related questions were added to the study instrument during the summer of 2013. The dependent variable for these analyses was engaging in NMPOU through any route of administration, based on responses to the question: "In the last 6 months, when you were using, which of the following non -injection prescription opiates did you use when they were not prescribed for you or that you took only for the 
experience or feeling they caused, and how often did you use them?" and "In the last 6 months, have you injected any of the following prescription opiates?" (yes vs. no). To identify factors associated with engaging in NMPOU, we considered a number of potential explanatory variables of interest. The following socio-demographic variables of interest were included: age (per year younger); sex; Caucasian ancestry; and homelessness, defined as having no fixed address, sleeping on the street, couch surfing, or staying in a shelter or hostel in the last 6 months. The following variables related to drug use were also included: any injection or non-injection heroin use; any injection or non-injection crack cocaine use; any injection or non-injection cocaine use; any injection or non-injection crystal methamphetamine use; binge drug use, defined as a period of using injection or non-injection drugs more often than usual; and experiencing a non-fatal drug overdose due to injection or non-injection drug use, based on responses to the question "In the last 6 months, have you overdosed by accident (i.e., where you had a negative reaction from using too much drugs)?". Behavioural and socio-structural risk factors hypothesized to be associated with NMPOU included: regular employment, defined as having a regular job, temporary work, or being self -employed; drug dealing, defined as selling drugs as a source of income; engaging in sex work, defined as exchanging sex for money, drugs, gifts, food, clothes, shelter or favours; incarceration, defined as being in detention, jail, or prison; and difficulty accessing services, based on responses to the question "In the last 6 months, was there a time you were in need of a service (e.g., housing, counselling) but could not obtain it?". All variables were binary and referred to activities, behaviours, and experiences in the previous 6 months unless otherwise indicated.

All analyses were conducted separately for ARYS and VIDUS participants, using cohort enrollment as a proxy marker for younger and older age groups, respectively. At the time of enrollment, ARYS participants must be between 14 and 26 years old; however, as a prospective cohort study with substantial resources devoted to maintaining follow-up, the ARYS participant pool necessarily includes participants who are older than 26 . These participants and their data are not excluded from the analyses given that this data provides a rich source for tracking and understanding long-term risk trajectories associated with street-involvement during a key developmental phase. While this practice may limit the applicability of our results to street-involved adolescents, we controlled for possible biases associated with these older participants in the youth cohort by including the continuous "per year younger" variable in the analyses to ensure that age differences within the cohort were accounted for. For consistency and to similarly control for a wide age range within the cohort, we also included the "per year younger" variable in the VIDUS analysis.
First, a descriptive analysis of the study sample was conducted using Pearson's chi-square test. Characteristics for participants who reported nonmedical prescription opioid use (NMPOU) were measured at their first visit (during the study period: 2013-2015), which involved a report of NMPOU; characteristics for all other participants were measured from the first study visit during the study period. Second, to model factors associated with engaging in NMPOU over time and to analyse longitudinal correlated within-subject data [38, 39], generalized estimating equation (GEE) analyses were performed. These methods provide standard errors adjusted by multiple observations per person using an exchangeable working correlation structure. The GEE estimating mechanism uses all available pairs method to encompass any missing data from dropouts or other intermittent missing. All non-missing pairs of data are used in the estimators of the working correlation parameters [40].

As a first step, GEE bivariate analyses were conducted to determine factors associated with engaging in NMPOU. Variables significant in the bivariate analyses at $p<0.10$ were considered for a full multivariate model. A backwards selection procedure was used to identify the model with the best overall fit as indicated by the lowest quasi-likelihood under the independence model criterion (QIC) value [41]. The QIC value was selected instead of the more recently developed Correlation Information Criterion (CIC), as the CIC is used to select the appropriate intracluster correlation structure, and is not used for covariate selection; we required a mechanism that could address both these needs simultaneously [42]. All statistical analyses were performed using SAS software version 9.4 (SAS, Cary, NC). All $p$-values were two sided.

\section{Results}

A total of 405 ARYS and 757 VIDUS participants were eligible for this study. For ARYS, 313 (77.3\%) participants were enrolled before December 2013 and 92 (22.7\%) participants were newly enrolled during the study period. For the 313 participants, the median age at the first study visit within the study period for the current analysis was 26 (IQR: 23-28); and for the 92 participants, the median age at study enrollment was 21 (IQR: 20-23). For VIDUS, 697 (92.1\%) participants were enrolled before December 2013 and 60 (7.9\%) participants were newly enrolled during the study period. Among these 697 participants, the median age at the first study visit within study period was 49 (IQR: 42-55); and for the 60 newly recruited participants, the median age at study enrollment was 31 (IQR: 28-34).

The number of ARYS participants with at least one study follow-up visit was 294 (72.6\%) and ARYS participants attended a median of 2 study visits (IQR: $1-3$ ). A 
total of 646 (85.3\%) VIDUS participants had at least one study follow-up visit and attended a median of 3 study visits (IQR: 2-3). The first ARYS observation used in this study was recorded on December 2, 2013 and the last observation was recorded on May 28, 2015. ARYS participants contributed a total of 889 observations, of which 239 (26.9\%) included a report of NMPOU. The first VIDUS observation used in this study was recorded on December 2, 2013 and the last was recorded on May 29, 2015. VIDUS participants contributed 1877 observations, of which 411 (21.9\%) included a report of NMPOU. Among 405 ARYS participants included in this analysis, $39.5 \% \quad(n=160)$ reported engaging in NMPOU throughout the study period. Among a total of 757 VIDUS participants, $34.6 \% \quad(n=262)$ reported engaging in NMPOU throughout the study period.

Among ARYS participants in this sample, 135 (33.3\%) were female, and 250 (61.7\%) were of Caucasian ethnicity; VIDUS participants were $33.9 \%(n=257)$ female and 59.7\% $(n=452)$ Caucasian. Descriptive statistics for younger (ARYS) and older (VIDUS) participants are displayed in Tables 1 and 2. The bivariate and multivariate analyses for younger participants are displayed in Table 3, and Table 4 displays the bivariate and multivariate analyses for older participants. In the multivariate analyses, engaging in NMPOU was independently and positively associated with the following factors among both younger and older participants: injection or non-injection heroin use (ARYS: Adjusted Odds Ratio [AOR] $=3.12$, 95\% Confidence Interval [CI]: 2.08-4.68; VIDUS: AOR $=2.79,95 \%$ CI: 2.08-3.74); drug dealing (ARYS: AOR $=2.22,95 \% \mathrm{CI}$ : 1.58-3.13; VIDUS: $\mathrm{AOR}=1.87,95 \% \mathrm{CI}: 1.40-2.49)$; and difficulty accessing services (ARYS: AOR $=1.47,95 \% \mathrm{CI}$ : 1.04-2.09; VIDUS: AOR = 1.74, 95\% CI: 1.32-2.29).

Factors positively and independently associated with NMPOU among younger (ARYS) participants only included: younger age ( $\mathrm{AOR}=1.12,95 \% \mathrm{CI}$ : $1.05-1.19)$; crack cocaine use (AOR $=1.56,95 \%$ CI: 1.06-2.30); and binge drug use (AOR $=1.41,95 \% \mathrm{CI}: 1.00-1.97)$. Among older (VIDUS) participants only, engaging in NMPOU was independently and positively associated with injection or non-injection crystal methamphetamine use $(\mathrm{AOR}=1.97,95 \% \mathrm{CI}$ : $1.46-2.66)$, non-fatal overdose $(\mathrm{AOR}=1.76,95 \% \mathrm{CI}: 1.20-2.60)$, and sex work $(\mathrm{AOR}=1.49,95 \% \mathrm{CI}: 1.00-2.22)$.

\section{Discussion}

Similar proportions of younger and older PWUD reported engaging in NMPOU in this study (40\% of ARYS; $35 \%$ of VIDUS), and in separate multivariate analyses, NMPOU was positively associated with heroin use, drug dealing, and difficulty accessing services among both age groups. In addition, younger participants who engaged in NMPOU were more likely to be younger, use crack

Table 1 Characteristics of younger participants stratified by engaging in nonmedical prescription opioid use over the study period, 2013-2015 ( $n=405)$

\begin{tabular}{|c|c|c|c|c|}
\hline \multirow[t]{2}{*}{ Characteristic $^{a}$} & \multirow{2}{*}{$\begin{array}{l}\text { Total }(\%) \\
(n=405)\end{array}$} & \multicolumn{2}{|c|}{ Nonmedical Prescription Opioid Use } & \multirow{2}{*}{$\begin{array}{l}p- \\
\text { value }\end{array}$} \\
\hline & & $\begin{array}{l}\text { Yes (\%) } \\
(n=160)\end{array}$ & $\begin{array}{l}\text { No (\%) } \\
(n=245)\end{array}$ & \\
\hline Age (M [IQR]) & $25(22-28)$ & $23(21-26)$ & $26(23-28)$ & $<0.001$ \\
\hline Any cocaine use $\mathrm{e}^{\mathrm{b}, \mathrm{c}}$ & $123(30.4)$ & $60(37.5)$ & $63(25.7)$ & 0.012 \\
\hline Any crack cocaine use $\mathrm{b}^{\mathrm{b}, \mathrm{c}}$ & $138(34.1)$ & $70(43.8)$ & $68(27.8)$ & $<0.001$ \\
\hline Any crystal meth use $\mathrm{e}^{\mathrm{b}, \mathrm{c}}$ & $268(66.2)$ & $121(75.6)$ & $147(60.0)$ & 0.001 \\
\hline Any heroin use $\mathrm{e}^{\mathrm{b}, \mathrm{c}}$ & $193(47.7)$ & $114(71.3)$ & 79 (32.2) & $<0.001$ \\
\hline Any non-fatal overdose $e^{b, c}$ & $93(23.0)$ & $54(33.8)$ & $39(15.9)$ & $<0.001$ \\
\hline Binge drug use $\mathrm{e}^{\mathrm{b}, \mathrm{c}}$ & $208(51.4)$ & $108(67.5)$ & $100(40.8)$ & $<0.001$ \\
\hline Caucasian ancestry & $250(61.7)$ & $100(62.5)$ & $150(61.2)$ & 0.796 \\
\hline Difficulty accessing services ${ }^{b, d}$ & $151(37.3)$ & $73(45.6)$ & $78(31.8)$ & 0.005 \\
\hline Drug dealing ${ }^{b}$ & $131(32.3)$ & $78(48.8)$ & $53(21.6)$ & $<0.001$ \\
\hline Female & $135(33.3)$ & 49 (30.6) & $86(35.1)$ & 0.350 \\
\hline Homeless $^{\mathrm{b}}$ & $202(49.9)$ & $95(59.4)$ & $107(43.7)$ & 0.002 \\
\hline Incarceration ${ }^{b}$ & $57(14.1)$ & $26(16.3)$ & $31(12.7)$ & 0.297 \\
\hline Regular employment ${ }^{\text {b }}$ & $191(47.2)$ & $81(50.6)$ & $110(44.9)$ & 0.259 \\
\hline Sex work ${ }^{\mathrm{b}}$ & $48(11.9)$ & $26(16.3)$ & $22(9.0)$ & 0.027 \\
\hline
\end{tabular}

a. Comparison is yes versus no unless otherwise specified

b. Refers to activities, behaviours, and experiences in the last six months

c. Includes injection and non-injection drug use

d. Includes health and social services 
Table 2 Characteristics of older participants stratified by engaging in nonmedical prescription opioid use over the study period, 2013-2015 $(n=757)$

\begin{tabular}{|c|c|c|c|c|}
\hline \multirow[t]{2}{*}{ Characteristic $^{a}$} & \multirow{2}{*}{$\begin{array}{l}\text { Total (\%) } \\
(n=757)\end{array}$} & \multicolumn{2}{|c|}{ Nonmedical Prescription Opioid Use } & \multirow{2}{*}{$\begin{array}{l}p- \\
\text { value }\end{array}$} \\
\hline & & $\begin{array}{l}\text { Yes }(\%) \\
(n=262)\end{array}$ & $\begin{array}{l}\text { No }(\%) \\
(n=495)\end{array}$ & \\
\hline Age (M [IQR]) & $48(40-55)$ & $47(38-53)$ & $49(41-56)$ & $<0.001$ \\
\hline Any cocaine use $e^{b, c}$ & $205(27.1)$ & $98(37.4)$ & 107 (21.6) & $<0.001$ \\
\hline Any crack cocaine use $e^{b, c}$ & $332(43.9)$ & $135(51.5)$ & $197(39.8)$ & 0.002 \\
\hline Any crystal meth use $\mathrm{b}^{\mathrm{b}, \mathrm{c}}$ & $223(29.5)$ & $124(47.3)$ & $99(20.0)$ & $<0.001$ \\
\hline Any heroin use $e^{b, c}$ & $362(47.8)$ & $200(76.3)$ & $162(32.7)$ & $<0.001$ \\
\hline Any non-fatal overdose $e^{b, c}$ & $60(7.9)$ & $43(16.4)$ & $17(3.4)$ & $<0.001$ \\
\hline Binge drug use $e^{b, c}$ & $235(31.0)$ & $118(45.0)$ & $117(23.6)$ & $<0.001$ \\
\hline Caucasian ancestry & $452(59.7)$ & $164(62.6)$ & $288(58.2)$ & 0.239 \\
\hline Difficulty accessing services ${ }^{b, d}$ & $149(19.7)$ & $78(29.8)$ & $71(14.3)$ & $<0.001$ \\
\hline Drug dealing ${ }^{b}$ & $171(22.6)$ & $95(36.3)$ & $76(15.4)$ & $<0.001$ \\
\hline Female & $257(33.9)$ & $92(35.1)$ & $165(33.3)$ & 0.622 \\
\hline Homeless $^{b}$ & $149(19.7)$ & $76(29.0)$ & $73(14.7)$ & $<0.001$ \\
\hline Incarceration ${ }^{b}$ & $51(6.7)$ & $28(10.7)$ & $23(4.6)$ & 0.002 \\
\hline Regular employment ${ }^{\mathrm{b}}$ & $202(26.7)$ & $59(22.5)$ & $143(28.9)$ & 0.059 \\
\hline Sex work & $72(9.5)$ & $36(13.7)$ & $36(7.3)$ & 0.004 \\
\hline
\end{tabular}

a. Comparison is yes versus no unless otherwise specified

b. Refers to activities, behaviours, and experiences in the last six months

c. Includes injection and non-injection drug use

d. Includes health and social services

Table 3 Bivariate and multivariate GEE analyses of factors associated with engaging in nonmedical prescription opioid use among younger participants $(n=405)$

\begin{tabular}{|c|c|c|c|c|}
\hline \multirow[t]{2}{*}{ Characteristic $^{a}$} & \multicolumn{2}{|l|}{ Unadjusted } & \multicolumn{2}{|l|}{ Adjusted } \\
\hline & $\begin{array}{l}\text { Odds Ratio } \\
(95 \% \text { Cl) }\end{array}$ & $p$-value & $\begin{array}{l}\text { Odds Ratio } \\
(95 \% \text { Cl) }\end{array}$ & $p$-value \\
\hline Age (per year younger) & $1.18(1.12-1.25)$ & $<0.001$ & $1.12(1.05-1.19)$ & $<0.001$ \\
\hline Any cocaine use $e^{b, c}$ & $1.68(1.18-2.39)$ & 0.004 & $1.31(0.88-1.95)$ & 0.181 \\
\hline Any crack use $e^{b, c}$ & $2.16(1.53-3.05)$ & $<0.001$ & $1.56(1.06-2.30)$ & 0.023 \\
\hline Any crystal meth use $\mathrm{e}^{\mathrm{b}, \mathrm{c}}$ & $2.06(1.42-2.98)$ & $<0.001$ & - & \\
\hline Any heroin use $\mathrm{e}^{\mathrm{b}, \mathrm{c}}$ & $4.82(3.34-6.96)$ & $<0.001$ & $3.12(2.08-4.68)$ & $<0.001$ \\
\hline Any non-fatal overdose $e^{b, c}$ & $2.24(1.61-3.12)$ & $<0.001$ & $1.43(0.97-2.10)$ & 0.070 \\
\hline Binge drug use $\mathrm{e}^{\mathrm{b}, \mathrm{c}}$ & $2.36(1.76-3.15)$ & $<0.001$ & $1.41(1.00-1.97)$ & 0.049 \\
\hline Caucasian ancestry & $1.24(0.85-1.80)$ & 0.269 & - & \\
\hline Difficulty accessing services ${ }^{b, d}$ & $1.70(1.27-2.27)$ & $<0.001$ & $1.47(1.04-2.09)$ & 0.030 \\
\hline Drug dealing ${ }^{b}$ & $2.76(2.03-3.75)$ & $<0.001$ & $2.22(1.58-3.13)$ & $<0.001$ \\
\hline Female & $0.91(0.61-1.36)$ & 0.662 & - & \\
\hline Homeless $^{\mathrm{b}}$ & $1.59(1.16-2.17)$ & 0.004 & - & \\
\hline Incarceration ${ }^{b}$ & $1.32(0.88-1.99)$ & 0.177 & - & \\
\hline Regular employment ${ }^{\mathrm{b}}$ & $1.23(0.92-1.64)$ & 0.168 & - & \\
\hline Sex work ${ }^{\mathrm{b}}$ & $2.11(1.35-3.29)$ & $<0.001$ & - & \\
\hline
\end{tabular}

a. Comparison is yes vs. no unless otherwise specified

b. Refers to behaviours, activities, and experiences in the last six months

c. Includes injection and non-injection use

d. Includes health and social services 
Table 4 Bivariate and multivariate GEE analyses of factors associated with engaging in nonmedical prescription opioid use among older participants $(n=757)$

\begin{tabular}{|c|c|c|c|c|}
\hline \multirow[t]{2}{*}{ Characteristic $^{a}$} & \multicolumn{2}{|l|}{ Unadjusted } & \multicolumn{2}{|l|}{ Adjusted } \\
\hline & $\begin{array}{l}\text { Odds Ratio } \\
(95 \% \text { Cl) }\end{array}$ & $p$-value & $\begin{array}{l}\text { Odds Ratio } \\
(95 \% \text { Cl) }\end{array}$ & $p$-value \\
\hline Age (per year younger) & $1.03(1.10-1.04)$ & $<0.001$ & $0.99(0.97-1.00)$ & 0.120 \\
\hline Any cocaine use $e^{b, c}$ & $1.53(1.18-1.99)$ & 0.001 & - & \\
\hline Any crack use $e^{b, c}$ & $1.42(1.12-1.81)$ & 0.004 & - & \\
\hline Any crystal meth use $\mathrm{e}^{\mathrm{b}, \mathrm{c}}$ & $2.95(2.25-3.88)$ & $<0.001$ & $1.97(1.46-2.66)$ & $<0.001$ \\
\hline Any heroin use $\mathrm{e}^{\mathrm{b}, \mathrm{c}}$ & $3.81(2.90-4.99)$ & $<0.001$ & $2.79(2.08-3.74)$ & $<0.001$ \\
\hline Any non-fatal overdose ${ }^{b, c}$ & $3.09(2.12-4.48)$ & $<0.001$ & $1.76(1.20-2.60)$ & 0.004 \\
\hline Binge drug use $e^{b, c}$ & $1.71(1.37-2.14)$ & $<0.001$ & - & \\
\hline Caucasian ancestry & $1.20(0.90-1.60)$ & 0.225 & - & \\
\hline Difficulty accessing services ${ }^{b, d}$ & $2.11(1.65-2.69)$ & $<0.001$ & $1.74(1.32-2.29)$ & $<0.001$ \\
\hline Drug dealing ${ }^{\mathrm{b}}$ & $2.75(2.10-3.58)$ & $<0.001$ & $1.87(1.40-2.49)$ & $<0.001$ \\
\hline Female & $0.97(0.73-1.31)$ & 0.864 & - & \\
\hline Homeless $^{\mathrm{b}}$ & $2.05(1.50-2.79)$ & $<0.001$ & - & \\
\hline Incarceration $^{\text {b }}$ & $2.28(1.47-3.54)$ & $<0.001$ & $1.55(0.98-2.44)$ & 0.061 \\
\hline Regular employment ${ }^{\mathrm{b}}$ & $0.78(0.60-1.00)$ & 0.055 & - & \\
\hline Sex work $^{b}$ & $2.05(1.41-2.98)$ & $<0.001$ & $1.49(1.00-2.22)$ & 0.049 \\
\hline
\end{tabular}

a. Comparison is yes vs. no unless otherwise specified

b. Refers to behaviours, activities, and experiences in the last six months

c. Includes injection and non-injection use

d. Includes health and social services

cocaine, and engage in binge drug use; older participants who engaged in NMPOU were more likely to use crystal methamphetamine, report a recent non-fatal overdose, and engage in sex work. While younger and older PWUD in these analyses shared risk factors for engaging in NMPOU, this study also found important differences between these two age groups that highlight opportunities to develop targeted efforts that address NMPOU and unique risks for each age group.

The association between NMPOU and age was not found to be statistically significant in the analysis of older participants, which suggests that birth cohorts were not a meaningful indicator of NMPOU among this sample. Conversely, the association between NMPOU and younger age was statistically significant among younger participants, and this finding may reflect recent trends where PO use is increasingly prevalent among young age groups $[4,12,43]$. The increasing use of POs has been attributed to the availability of POs $[4,17,44]$, although the increased risk for younger birth cohorts using POs may be more strongly related to the linkages between youth observing their parents modelling substance use (i.e., PO use) and then concluding that PO use is safe [4]. Preventing initiation into injection drug use for youth who engage in NMPOU is key to reducing the sequelae of harms associated with intensifying substance use, and future research investigating prevention mechanisms is needed.
Younger and older participants who engaged in NMPOU were significantly more likely to use heroin, which previous research has found to be used as a replacement for POs when PO availability is low [45]. Although heroin and POs are both opioids and central nervous system depressants, POs are originally obtained from regulated healthcare sources, and heroin is only available through unregulated illegal drug markets. Acquiring substances from the street is especially problematic in our study setting, where the toxic synthetic opioid fentanyl has adulterated a substantial proportion of the illegal drug supply [46, 47], and fentanyl-related overdose mortality has increased alarmingly in various settings across Canada and the United States [48-51]. To reduce reliance on illegal heroin, oral medications such as buprenorphine/naloxone (Suboxone), methadone, naltrexone, and slow release morphine have been recommended in recent opioid treatment guidelines as effective treatments [52], and injectable opioids such as diacetylmorphine and hydromorphone are emerging as options for treatment -refractory opioid dependence [53, 54]. The international and North American evidence base for heroin assisted treatment (diacetylmorphine) is strong [53-55], and although less research has been conducted on hydromorphone as an injectable opioid treatment, scaling up these treatments may be an important tool to reduce NMPOU and exposure to contaminated illegal drugs in Vancouver. 
It is important to note that PWUD have long advocated for access to a wider spectrum of opioid agonist treatments through collaborations with researchers and coordinated advocacy efforts [56-61]. This study did not control for intentional or unintentional exposure to fentanyl or other illicitly manufactured synthetic opioids, and future research using the ARYS and VIDUS cohorts would benefit from including exposure to fentanyl in analyses.

More differences than similarities were found with illegal substance use patterns between younger and older participants. Despite both younger and older PWUD who engaged in NMPOU being significantly more likely to engage in heroin use, younger participants who engaged in NMPOU were more likely to also engage in crack cocaine use and binge drug use, while older participants were more likely to use crystal methamphetamine in addition to engaging in NMPOU. Crystal methamphetamine use may be an important marker of risk for NMPOU among older individuals in Vancouver, and this finding is concerning given local reports of increasing crystal methamphetamine use among adults in Vancouver [62-64]. Historically, crystal methamphetamine use has been more prevalent among street-involved youth in Vancouver [36], as $66 \%$ of all participants in the younger age group reported using crystal methamphetamine at baseline; in addition, crystal methamphetamine has been associated with initiating injection drug use among this cohort of youth [65].

The findings from the multivariate model indicate that NMPOU among younger participants was not associated with a significantly increased risk for non-fatal overdose, whereas older participants who engaged in NMPOU were significantly more likely to report a recent non-fatal overdose; however, it should be noted that the confidence intervals for these adjusted odds ratios overlap considerably and these findings may be attributable to differences in selection criteria for the ARYS and VIDUS cohorts. This null result for youth was unexpected given the increased rate of overdose associated with PO use [66], and that the comparison group in this analysis included non-opioid users. These findings align with previous research findings that older age is associated with mortality due to unintentional PO -related overdose [67]. Further research investigating protective factors associated with a lower risk of overdose among youth who engage in NMPOU is needed, which may include specific routes of administration or harm reducing practices related to using a substance with a known dosage and purity (e.g., prescription opioids versus unregulated heroin of unknown purity and composition). Regardless, harm reduction services are critical to ensure that older PWUD, as well as younger PWUD, who engage in NMPOU have access to overdose prevention and reversal services such as supervised drug consumption spaces/ services and the widespread distribution of Naloxone/Narcan in the community and among PWUD. The reach of harm reduction services may also be increased by strategically mobilizing key peers within PWUDs' social networks, which are an untapped resource and could become important facilitators of harm reduction supplies and information $[68,69]$.

Improved access to health and social services is also especially important in Vancouver, as this study found that older and younger PWUD who engage in NMPOU were more likely to report difficulty accessing services. Despite a saturation of services in the neighbourhoods where ARYS and VIDUS participants primarily live and congregate (the Downtown South and Downtown Eastside, respectively), there remain important gaps in service design and access. Previous research among youth in the ARYS cohort found that local youth-focused shelters and housing services had strict rules governing entry into- and continued use of- the service that deterred participants; conversely, adult or non-youth-specific services were perceived as unsafe or inappropriate for youth [70]. Qualitative research among the VIDUS cohort has found that a local supervised injection site often has long wait times that result in people giving up and using drugs elsewhere [71] and "area restrictions" used by police to prohibit entry into "drug scenes" impedes access to services and supports tailored for PWUD and are often specifically located in areas with high drug use [72]. This finding among younger PWUD is consistent with previous research from around the world; youth who use illegal drugs often experience difficulty accessing services due to stigma and discrimination from service providers, as well as a lack of youth-centric health and social services that are preferred but not widely available [73, 74]. Although the results indicate high rates of illegal polysubstance use in the ARYS and VIDUS cohorts, participants who only engage in NMPOU may experience additional difficulties accessing harm reduction services that are tailored to people who use illegal drugs, since they and their social networks may be outside the scope of outreach activities conducted by these services $[75,76]$. More research is required to better understand specific barriers to accessing health and social services among youth and adults who engage in NMPOU, as well as inform effective solutions to fill an important service gap for these individuals.

Participants in both age groups who engage in NMPOU were more likely to report recent drug dealing, and older participants were more likely to report sex work. Drug dealing has been associated with more intense substance use among PWUD of Caucasian or white ethnicity [77], and dealing illegal drugs has been associated with a higher likelihood of NMPOU among American youth [78]. Our findings reflect the well-established relationship between socio-economic marginalization and drug dealing [40,79], 
and align with consistent research findings that income from drug dealing [80] and sex work [81] is often used to sustain ongoing substance use. Despite aligning with previous research, it is not clear why drug dealing and sex work remained significantly associated with engaging in NMPOU after controlling for other illegal drug use; more research is needed investigating NMPOU and income generation among individuals not typically recruited in population-level surveys. Given that difficulty accessing services was also significantly associated with NMPOU among younger and older participants, there is a clear need to improve employment and other services for PWUD who engage in NMPOU as an intervention to increase socio-economic independence, particularly among people who engage in sex work. Similar efforts to facilitate entry into evidence-based addiction treatments for opioid use such as opioid agonist treatment, heroin assisted treatment, and injectable opioid therapy may reduce the prevalence of NMPOU and risky income generating activities.

As there is a lack of evidence to support the effectiveness of POs for treating chronic pain [82], safer prescribing to limit the supply and availability of POs is important for reducing the incidence and prevalence of NMPOU in the study setting. However, as the supply of POs becomes more restricted, close surveillance and a suite of interventions are needed to ensure that those who engage in NMPOU are not at greater risk for substituting PO use with contaminated illegal drugs that have increased overdose risks. Low barrier harm reduction services to connect with those who engage in NMPOU and have had difficulty accessing services may also be an important link to supportive healthcare services, social services, and a range of treatment options for opioid use among younger and older age groups. In addition, future research investigating the correlates of incident and recurrent NMPOU over time is needed to better understand how access to services and changes in healthcare practices impact NMPOU among high-risk individuals who use illegal drugs.

There are limitations to this research. First, ARYS and VIDUS participants may not be representative of all PWUD in Vancouver and the results therefore not generalizable to other settings in the city. However, extensive street-based and outreach efforts were undertaken in order to recruit a representative sample, and the socio-demographic characteristics of participants in the ARYS and VIDUS studies are similar to other studies in Vancouver [83, 84]. Second, this study compares data from two cohort studies with different inclusion criteria, which may result in cohort or selection effects. These cohort effects may affect the results related to homelessness and injection drug use, as these risk factors are also inclusion criteria for ARYS and VIDUS, respectively. Given the longitudinal nature of these cohort studies and extensive efforts to track participants over multiple study visits, the ARYS and VIDUS studies have observed changes in behaviours and risk factors over time. For example, we have previously reported on transitions out of homelessness among ARYS participants [85] and injection cessation among VIDUS participants [86, 87]. In addition, ARYS and VIDUS have previously been combined in quantitative and qualitative analyses [72, 88-90]. Third, social desirability and recall bias may have resulted in erroneous reporting of our outcome and independent variables. Previous research on substance use has found discrepancies between self-reported substance use and bioassay test results among American adult male arrestees [91] and noted concerns that youth may not be truthful about substance use when speaking with authority figures who are able to assign punishment [92]. Despite these findings, self-reported substance use, criminality, and HIV-related risk-taking among PWUD has also been deemed sufficiently reliable and valid [93]. Training and engaging PWUD ("peers") in survey administration and data collection methods when conducting substance use research may be an important mechanism to reduce social desirability response biases and increase capacity within communities of PWUD [94, 95]. To reduce socially desirable reporting from participants, the ARYS and VIDUS interviewers are trained in building trust and rapport, and study instruments situate sensitive questions towards the end of the questionnaire to allow interviewers to build rapport with participants. Although some socially desirable reporting is inevitable, any such reporting from participants would be expected to under-estimate the prevalence of sensitive risk factors and therefore our findings likely represent conservative estimates. Less is known about the accuracy of self-reporting NMPOU among PWUD; however, efforts to improve the accuracy of reporting NMPOU among ARYS and VIDUS participants included using both the generic and brand name of POs, and showing pictures of a wide variety of POs during study visits. Fourth, no other information about the circumstances surrounding non-fatal overdose were included in this analysis (e.g., what substance was used at the time of overdose, whether substances were used alone or with another person, or whether fentanyl contributed to the overdose); however, the focus of this study was whether recent NMPOU was an independent marker for overdose among other risk factors. A more detailed investigation of the circumstances of overdose among people who engage in NMPOU is outside the scope of this analysis but is a promising direction for future research.

\section{Conclusions}

The shared risk factors among younger and older participants who engage in NMPOU underscore the importance of addressing barriers to accessing health and social 
services, as people who engage in NMPOU appear to be particularly under-supported and under-served by existing services for PWUD. Adult PWUD who engage in NMPOU are also at greater risk of overdose, which highlights the need for youth and adult-specific strategies that focus on reducing high intensity substance use among youth and providing low barrier overdose prevention and reversal services for adults. There is an urgent need to design and implement initiatives to improve healthcare providers' skills with managing and treating substance dependence [96], as well as developing pain treatment strategies tailored for PWUD [26]. In addition to developing services that address youths' and adults' unique needs, policy-makers and healthcare providers are urged to reduce systematic barriers to a range of addiction treatment options for opioid use that may contribute to reductions in the prevalence of NMPOU and provide an additional benefit of preventing other PWUD from initiating injection drug use [97].

\begin{abstract}
Abbreviations
AOR: Adjusted Odds Ratio; ARYS: At-Risk Youth Study; Cl: Confidence Interval; GEE: Generalized Estimating Equation; IQR: Inter-Quartile Range; NMPOU: Non -Medical Prescription Opioid Use; PO: Prescription Opioid; PWUD: People who use Illegal Drugs; QIC: Quasi-Likelihood under the Independence model Criterion; VIDUS: Vancouver Injection Drug Users Study
\end{abstract}

\section{Acknowledgments}

The authors thank the ARYS and VIDUS study participants for their contribution to the research, as well as current and past researchers and staff. Special thanks are also extended to Dr. Robert Hogg who provided valuable advice on this manuscript. Dr. Kora DeBeck is supported by a MSFHR / St. Paul's Hospital Foundation-Providence Health Care Career Scholar Award and a Canadian Institutes of Health Research (CIHR) New Investigator Award. Dr. Will Small is supported by a Michael Smith Foundation for Health Research Career Investigator Scholar Award. Dr. Kanna Hayashi is supported by a ClHR New Investigator Award (MSH-141971) and a Michael Smith Foundation for Health Research (MSFHR) Scholar Award.

\section{Funding}

This work was supported by the US National Institutes of Health under Grant U01DA038886; and Canadian Institutes of Health Research under Grant MOP-286532.

\section{Availability of data and materials}

The datasets generated and analysed during the current study are not publicly available due to assurances of strict confidentiality given to participants during the informed consent process.

\section{Authors' contributions}

TC contributed to the study design, statistical analyses, and took primary responsibility for preparing the manuscript. $\mathrm{HD}$ and $\mathrm{EN}$ were responsible for conducting the statistical analyses. WS, HD, EN, KH, and KD contributed substantially to the study design and main content of the manuscript. All authors read and approved the final manuscript.

\section{Authors' information}

Not applicable.

\section{Ethics approval and consent to participate}

All participants gave informed consent before enrolling in ARYS and VIDUS. The ARYS and VIDUS studies have been approved by the University of British Columbia/Providence Health Care Research Ethics Board.
Consent for publication

Not applicable.

\section{Competing interests}

The authors declare that they have no competing interests.

\section{Publisher's Note}

Springer Nature remains neutral with regard to jurisdictional claims in published maps and institutional affiliations.

\section{Author details}

${ }^{1}$ Faculty of Health Sciences, Simon Fraser University, Blusson Hall, Room 11300, 8888 University Drive, Burnaby, BC V5A 156, Canada. ${ }^{2}$ British Columbia Centre on Substance Use, Providence Health Care, 400-1045 Howe St, Vancouver, BC V6Z 2A9, Canada. ${ }^{3}$ School of Population and Public Health, University of British Columbia, 2206 East Mall, Vancouver, BC V6T 1Z3, Canada. ${ }^{4}$ Centre for Applied Research in Mental Health and Addiction, SFU Faculty of Health Sciences, 515 W. Hastings Street, Vancouver, BC V6B 5K3, Canada. ${ }^{5}$ School of Public Policy, Simon Fraser University, 515 West Hastings Street, Suite 3271, Vancouver, BC V6B 5K3, Canada.

Received: 22 May 2018 Accepted: 13 November 2018 Published online: 27 November 2018

\section{References}

1. Rudd RA, Seth P, David F, Scholl L. Increases in drug and opioid-involved overdose deaths - United States, 2010-2015. MMWR Morb Mortal Wkly Rep. 2016;65:1445-52.

2. Nolan S, Socias ME, Wood E. The Threat of an International Opioid Crisis. Current Addiction Reports; 2018.

3. Meier EA, Troost JP, Anthony JC. Extramedical use of prescription pain relievers by youth aged 12 to 21 years in the United States: national estimates by age and by year. Arch Pediatr Adolesc Med. 2012;166(9):803-7.

4. Miech R, Bohnert A, Heard K, Boardman J. Increasing use of nonmedical analgesics among younger cohorts in the United States: a birth cohort effect. J Adolesc Health. 2013;52(1):35-41.

5. Fischer B, lalomiteanu A, Kurdyak P, Mann RE, Rehm J. Reductions in nonmedical prescription opioid use among adults in Ontario, Canada: are recent policy interventions working? Subst/ Abus Treatment Prev Pol. 2013;8:4.

6. Currie $\mathrm{CL}$, Wild TC. Adolescent use of prescription drugs to get high in Canada. Can J Psychiatry. 2012;57(12):745-51.

7. Schepis TS, Krishnan-Sarin S. Characterizing adolescent prescription misusers: a population-based study. J Am Acad Child Adolesc Psychiatr. 2008;47(7):745-54

8. Veliz PT, Boyd C, McCabe SE. Playing through pain: sports participation and nonmedical use of opioid medications among adolescents. Am J Public Health. 2013;103(5):e28-30.

9. Deandrea DC, Troost JP, Anthony JC. Toward primary prevention of extramedical OxyContin(R) use among young people. Prev Med. 2013;57(3):244-6.

10. Back SE, Payne RL, Simpson AN, Brady KT. Gender and prescription opioids: findings from the National Survey on drug use and health. Addict Behav. 2010;35(11):1001-7.

11. Shield KD, lalomiteanu A, Fischer B, Mann RE, Rehm J. Non-medical use of prescription opioids among Ontario adults: data from the 2008/2009 CAMH Monitor. Can J Public Health = Revue canadienne de sante publique. 2011;102(5):330-5.

12. Martins SS, Keyes KM, Storr CL, Zhu H, Grucza RA. Birth-cohort trends in lifetime and past-year prescription opioid-use disorder resulting from nonmedical use: results from two national surveys. I Stud Alcohol Drugs. 2010;71(4):480-7.

13. Suryaprasad AG, White JZ, Xu FJ, Eichler BA, Hamilton J, Patel A, et al. Emerging epidemic of hepatitis $C$ virus infections among young nonurban persons who inject drugs in the United States, 2006-2012. Clin Infect Dis. 2014:59(10):1411-9.

14. Back SE, Lawson KM, Singleton LM, Brady KT. Characteristics and correlates of men and women with prescription opioid dependence. Addict Behav. 2011;36(8):829-34.

15. Osgood ED, Eaton TA, Trudeau JJ, Katz NP. A brief survey to characterize oxycodone abuse patterns in adolescents enrolled in two substance abuse recovery high schools. Am J Drug Alcohol Abuse. 2012;38(2):166-70. 
16. Cerdá M, Santaella J, Marshall BDL, Kim JH, Martins SS. Nonmedical Prescription Opioid Use in Childhood and Early Adolescence Predicts Transitions to Heroin Use in Young Adulthood: A National Study. J Pediatr. 2015;167(3):605-12.e1 2.

17. Lankenau SE, Teti M, Silva K, Bloom JJ, Harocopos A, Treese M. Initiation into prescription opioid misuse amongst young injection drug users. Int J Drug Policy. 2012;23(1):37-44.

18. Lawson KM, Back SE, Hartwell KJ, Maria MMS, Brady KT. A comparison of trauma profiles among individuals with prescription opioid, nicotine, or cocaine dependence. Am J Addict. 2013;22(2):127-31.

19. Caviness CM, Anderson BJ, de Dios MA, Kurth M, Stein M. Prescription medication exchange patterns among methadone maintenance patients. Drug Alcohol Depend. 2013;127(1-3):232-8.

20. Arnett JJ. Emerging adulthood: what is it, and what is it good for? Child Dev Perspect. 2007;1(2):68-73.

21. Degenhardt $L$, Stockings E, Patton G, Hall WD, Lynskey M. The increasing global health priority of substance use in young people. The Lancet Psychiatry. 2016;3(3):251-64.

22. Saha TD, Kerridge BT, Goldstein RB, Chou SP, Zhang H, Jung J, et al. Nonmedical prescription opioid use and DSM-5 nonmedical prescription opioid use disorder in the United States. J Clin Psychiatry. 2016;77(6):772-80.

23. Chau DL, Walker V, Pai L, Cho LM. Opiates and elderly: use and side effects. Clin Interv Aging. 2008;3(2):273-8.

24. Han B, Compton WM, Blanco C, Crane E, Lee J, Jones CM. Prescription opioid use, misuse, and use disorders in u.s. adults: 2015 national survey on drug use and health. Ann Intern Med. 2017;167(5):293-301.

25. Lake S, Milloy MJ, Dong H, Hayashi K, Wood E, Kerr T, et al. Initiation into prescription opioid injection and associated trends in heroin use among people who use illicit drugs. Drug Alcohol Depend. 2016;169:73-9.

26. Voon P, Callon C, Nguyen P, Dobrer S, Montaner JS, Wood E, et al. Denial of prescription analgesia among people who inject drugs in a Canadian setting. Drug Alcohol Rev. 2015;34(2):221-8.

27. Voon P, Callon C, Nguyen P, Dobrer S, Montaner J, Wood E, et al. Selfmanagement of pain among people who inject drugs in Vancouver. Pain Manag. 2014;4(1):27-35.

28. DeBeck K, Wood E, Dong H, Dobrer S, Hayashi K, Montaner J, et al. Nonmedical prescription opioid use predicts injection initiation among streetinvolved youth. Int J Drug Policy. 2016;34:96-100.

29. Silva K, Schrager SM, Kecojevic A, Lankenau SE. Factors associated with history of non-fatal overdose among young nonmedical users of prescription drugs. Drug Alcohol Depend. 2013;128(1-2):104-10.

30. Fischer B, Patra J, Cruz MF, Gittins J, Rehm J. Comparing heroin users and prescription opioid users in a Canadian multi-site population of illicit opioid users. Drug And Alcohol Rev. 2008;27(6):625-32.

31. Havens JR, Lofwall MR, Frost SDW, Oser CB, Leukefeld CG, Crosby RA. Individual and network factors associated with prevalent hepatitis $C$ infection among rural Appalachian injection drug users. Am J Public Health. 2013;103(1):e44-52.

32. Gwin Mitchell S, Kelly SM, Brown BS, Schacht Reisinger H, Peterson JA, Ruhf $A$, et al. Uses of diverted methadone and buprenorphine by opioidaddicted individuals in Baltimore, Maryland. Am J Addict. 2009;18(5):346-55.

33. Young AM, Havens JR, Leukefeld CG. A comparison of rural and urban nonmedical prescription opioid users' lifetime and recent drug use. Am J Drug and Alcohol Abuse. 2012;38(3):220-7.

34. Pollini RA, Banta-Green CJ, Cuevas-Mota J, Metzner M, Teshale E, Garfein RS. Problematic use of prescription-type opioids prior to heroin use among young heroin injectors. Subst Abus Rehabil. 2011;2:173-80.

35. Rhodes T, Lilly R, Fernandez C, Giorgino E, Kemmesis UE, Ossebaard HC, et al. Risk factors associated with drug use: the importance of 'risk environment'. Drug-Educ Prev Polic. 2003;10(4):303-29.

36. Wood E, Stoltz J-A, Montaner J, Kerr T. Evaluating methamphetamine use and risks of injection initiation among street youth: the ARYS study. Harm Reduct J. 2006;3(1):18.

37. Strathdee SA, Patrick DM, Currie SL, Cornelisse PG, Rekart ML, Montaner JS, et al. Needle exchange is not enough: lessons from the Vancouver injecting drug use study. AIDS. 1997;11(8):F59-65.

38. Ballinger GA. Using generalized estimating equations for longitudinal data analysis. Organ Res Methods. 2004;7(2):127-50.

39. Hanley JA, Negassa A, Edwardes MD, Forrester JE. Statistical analysis of correlated data using generalized estimating equations: an orientation. Am J Epidemiol. 2003;157(4):364-75.
40. Ferguson KM, Bender K, Thompson SJ, Maccio EM, Pollio D. Employment status and income generation among homeless young adults. Youth Soc. 2011:44(3):385-407.

41. Pan W. Akaike's information criterion in generalized estimating equations. Biometrics. 2001;57(1):120-5.

42. Hin L-Y, Wang $Y$-G. Working-correlation-structure identification in generalized estimating equations. Stat Med. 2008;28(4):642-58.

43. Fischer B, lalomiteanu A, Boak A, Adlaf E, Rehm J, Mann RE. Prevalence and key covariates of non-medical prescription opioid use among the general secondary student and adult populations in Ontario, Canada. Drug And Alcohol Rev. 2013;32(3):276-87.

44. Substance Abuse and Mental Health Services Administration. Results from the 2009 National Survey on Drug Use and Health: Volume I. Summary of National Findings. Rockville, MD: (Office of Applied Studies - NSDUH Series H-38A, HHS Publication No. SMA 10-4586 Findings); 2010.

45. Cicero TJ, Ellis MS, Surratt HL, Kurtz SP. The changing face of heroin use in the United States: a retrospective analysis of the past 50 years. JAMA Psychiatry. 2014;71(7):821-6.

46. Fairbairn N, Coffin PO, Walley AY. Naloxone for heroin, prescription opioid, and illicitly made fentanyl overdoses: Challenges and innovations responding to a dynamic epidemic. Int J Drug Policy. 2017:46(Supplement C):172-9.

47. Lysyshyn M, Dohoo C, Forsting S, Kerr T, McNiel R, editors. Evaluation of a fentanyl drug checking program for clients of a supervised injection site, Vancouver, Canada. Montreal: Harm reduction international; 2017.

48. British Columbia Coroners Service. Fentanyl-detected illicit drug overdose deaths January 1, 2012 to august 31, 2017. Burnaby, BC: Ministry of Public Safety and Solicitor General; 2017.

49. Ciccarone D. Fentanyl in the US heroin supply: a rapidly changing risk environment. Int J Drug Policy. 2017;46:107-11.

50. Centers for Disease Control and Prevention. Increases in Fentanyl Drug Confiscations and Fentanyl-related Overdose Fatalities [press release]. Atlanta: Office of Public Health Preparedness and Response; 2015.

51. Fischer B, Vojtila L, Rehm J. The 'fentanyl epidemic' in Canada - some cautionary observations focusing on opioid-related mortality. Prev Med. 2018;107:109-13.

52. British Columbia Centre on Substance Use and B.C. Ministry of Health. Vancouver: A Guideline for the Clinical Management of Opioid Use Disorder; 2017.

53. Oviedo-Joekes E, Guh D, Brissette S, Marchand K, MacDonald S, Lock K, et al. Hydromorphone compared with diacetylmorphine for long-term opioid dependence: a randomized clinical trial. JAMA psychiatry. 2016;73(5):447-55.

54. Oviedo-Joekes E, Brissette S, Marsh DC, Lauzon P, Guh D, Anis A, et al. Diacetylmorphine versus methadone for the treatment of opioid addiction. New Engl J Med. 2009;361(8):777-86.

55. Ferri M, Davoli M, Perucci CA. Heroin maintenance for chronic heroindependent individuals. Cochrane Database Syst Rev. 2010;(8):Cd003410. https://doi.org/10.1002/14651858.CD003410.pub3.

56. Thomson E, Lampkin H, Maynard R, Karamouzian M, Jozaghi E. The lessons learned from the fentanyl overdose crises in British Columbia, Canada. Addiction. 2017;112(11):2068-70.

57. Jozaghi E, Greer AM, Lampkin H, Buxton JA. Activism and scientific research: 20 years of community action by the Vancouver area network of drug users. Subst Abuse Treat Prev Policy. 2018;13(1):18.

58. Jozaghi $E$, Marsh S. Missing the trends in the fentanyl overdose crisis: The need for immediate intervention in small and rural communities. Can J Public Health = Revue canadienne de sante publique. 2017;108(4):e457.

59. Boyd S, Association NP. Yet they failed to do so: recommendations based on the experiences of NAOMI research survivors and a call for action. Harm Reduct J. 2013;10(1):6.

60. Boyd S, Murray D, Snap, MacPherson D. Telling our stories: heroin-assisted treatment and SNAP activism in the Downtown Eastside of Vancouver. Harm Reduct J. 2017;14:27.

61. McNeil R, Kerr T, Anderson S, Maher L, Keewatin C, Milloy MJ, et al. Negotiating structural vulnerability following regulatory changes to a provincial methadone program in Vancouver, Canada: a qualitative study. Soc Sci Med. 2015;133:168-76.

62. Woo A. The quiet rise of crystal meth. The Globe and Mail; 2016.

63. Amlani A, McKee G, Khamis N, Raghukumar G, Tsang E, Buxton JA. Why the FUSS (fentanyl urine screen study)? A cross-sectional survey to characterize an emerging threat to people who use drugs in British Columbia, Canada. Harm Reduct J. 2015;12(1):54.

64. Merali F. 'The elephant in the room': crystal meth use in Vancouver rises 600\% over last decade. CBC News; 2017. 
65. Werb D, Kerr T, Buxton J, Shoveller J, Richardson C, Montaner J, et al. Crystal methamphetamine and initiation of injection drug use among streetinvolved youth in a Canadian setting. CMAJ : Canadian Medical Association Journal. 2013;185(18):1569-75.

66. Rudd RA, Aleshire N, Zibbell JE, Matthew GR. Increases in drug and opioid overdose deaths_-United States, 2000-2014. Am J Transplant. 2016;16(4):1323-7.

67. Paulozzi LJ, Kilbourne EM, Shah NG, Nolte KB, Desai HA, Landen MG, et al. A history of being prescribed controlled substances and risk of drug overdose death. Pain medicine (Malden, Mass). 2012;13(1):87-95.

68. Brothers S. Merchants, samaritans, and public health workers: secondary syringe exchanger discursive practices. Int J Drug Policy. 2016;37:1-8.

69. Bouchard M, Hashimi S, Tsai K, Lampkin H, Jozaghi E. Back to the core: a network approach to bolster harm reduction among persons who inject drugs. Int J Drug Policy. 2018;51:95-104.

70. Krüsi A, Fast D, Small W, Wood E, Kerr T. Social and structural barriers to housing among street-involved youth who use illicit drugs. Health Soc Care community. 2010;18(3):282-8.

71. Small W, Shoveller J, Moore D, Tyndall M, Wood E, Kerr T. Injection drug users' access to a supervised injection facility in Vancouver, Canada: the influence of operating policies and local drug culture. Qual Health Res. 2011;21(6):743-56

72. McNeil R, Cooper H, Small W, Kerr T. Area restrictions, risk, harm, and health care access among people who use drugs in Vancouver, Canada: a spatially oriented qualitative study. Health Place. 2015;35:70-8.

73. Krug A, Hildebrand M, Sun N. "We don't need services. We have no problems": exploring the experiences of young people who inject drugs in accessing harm reduction services. J Int AIDS Soc. 2015;18:19442 (1758-2652 (Electronic)).

74. Merkinaite S, Grund JP, Frimpong A. Young people and drugs: next generation of harm reduction. Int J Drug Policy. 2010;21(2):112-4.

75. Frank D, Mateu-Gelabert P, Guarino H, Bennett A, Wendel T, Jessell L, et al. High risk and little knowledge: overdose experiences and knowledge among young adult nonmedical prescription opioid users. 2015(1873-4758 (Electronic)).

76. Bruneau J, Roy E, Arruda N, Zang G, Jutras-Aswad D. The rising prevalence of prescription opioid injection and its association with hepatitis $C$ incidence among street-drug users. Addiction. 2012;107(7):1318-27.

77. Floyd LJ, Alexandre PK, Hedden SL, Lawson AL, Latimer WW, Giles N. Adolescent drug dealing and race/ethnicity: a population-based study of the differential impact of substance use on involvement in drug trade. Am J Drug and Alcohol Abuse. 2010;36(2):87-91.

78. Sung HE, Richter L, Vaughan R, Johnson PB, Thom B. Nonmedical use of prescription opioids among teenagers in the United States: trends and correlates. J Adolesc Health. 2005;37(1):44-51.

79. DeBeck K, Shannon K, Wood E, Li K, Montaner J, Kerr T. Income generating activities of people who inject drugs. Drug Alcohol Depend. 2007;91(1):50-6.

80. Werb D, Kerr T, Li K, Montaner J, Wood E. Risks surrounding drug trade involvement among street-involved youth. Am J Drug Alcohol Ab. 2008; 34(6):810-20.

81. Deering KN, Shoveller J, Tyndall MW, Montaner JS, Shannon K. The street cost of drugs and drug use patterns: relationships with sex work income in an urban Canadian setting. Drug Alcohol Depend. 2011;118(2-3):430-6.

82. Dowell D, Haegerich TM, Chou R. CDC guideline for prescribing opioids for chronic pain—United States, 2016. JAMA. 2016;315(15):1624-45.

83. Ochnio JJ, Patrick D, Ho M, Talling DN, Dobson SR. Past infection with hepatitis a virus among Vancouver street youth, injection drug users and men who have sex with men: implications for vaccination programs. Can Med Assoc J. 2001;165(3):293-7.

84. Miller CL, Strathdee SA, Kerr T, Li K, Wood E. Factors associated with early adolescent initiation into injection drug use: implications for intervention programs. J Adolesc Health. 2006;38(4):462-4.

85. Cheng T, Wood E, Feng C, Mathias S, Montaner J, Kerr T, et al. Transitions into and out of homelessness among street-involved youth in a Canadian setting. Health Place. 2013;23:122-7.

86. Werb D, Kerr T, Buxton J, Shoveller J, Richardson C, Montaner J, et al. Patterns of injection drug use cessation during an expansion of syringe exchange services in a Canadian setting. Drug Alcohol Depend. 2013;132(3):535-40.

87. DeBeck K, Kerr T, Li K, Milloy MJ, Montaner J, Wood E. Incarceration and drug use patterns among a cohort of injection drug users. Addiction. 2008;104(1):69-76.

88. Marshall BDL, Wood E, Shoveller JA, Patterson TL, Montaner JSG, Kerr T. Pathways to HIV risk and vulnerability among lesbian, gay, bisexual, and transgendered methamphetamine users: a multi-cohort gender-based analysis. BMC Public Health. 2011;11(1):20.

89. Ti L, Socías ME, Wood E, Milloy MJ, Nosova E, DeBeck K, et al. The impact of methadone maintenance therapy on access to regular physician care regarding hepatitis $\mathrm{C}$ among people who inject drugs. PLoS One. 2018;13(3):e0194162.

90. Nolan S, Dias Lima V, Fairbairn N, Kerr T, Montaner J, Grebely J, et al. The impact of methadone maintenance therapy on hepatitis $C$ incidence among illicit drug users. Addiction. 2014;109(12):2053-9.

91. Hunt DE, Kling R, Almozlino Y, Jalbert S, Chapman MT, Rhodes W. Telling the truth about drug use: how much does it matter? J Drug Issues. 2015;45(3):314-29.

92. Harris B, Shaw B, Lawson H, Sherman B. Barriers to addressing adolescent substance use: perceptions of New York school-based health center providers. J Sch Health. 2016;86(2):96-104.

93. Darke S. Self-report among injecting drug users: a review. Drug Alcohol Depend. 1998:51(3):253-63.

94. Jozaghi E, Buxton JA, Thomson E, Marsh S, Gregg D, Bouchard M. Building new approaches to risk reduction with social networks and people who smoke illegal drugs from participatory community-based research. Int J Qual Methods. 2018;17(1):1609406918771247.

95. Damon W, Callon C, Wiebe L, Small W, Kerr T, McNeil R. Community-based participatory research in a heavily researched inner city neighbourhood: perspectives of people who use drugs on their experiences as peer researchers. Soc Sci Med. 2017;176:85-92.

96. Jozaghi E, Dadakhah-Chimeh Z. A call for action to combat the growing synthetic opioid epidemic: the need for the creation and expansion of addiction and psychiatric nursing programs. J Sch Nurs. 2017;34(1):11-3.

97. Werb D, Buxton J, Shoveller J, Richardson C, Rowell G, Wood E. Interventions to prevent the initiation of injection drug use: a systematic review. Drug Alcohol Depend. 2013;133(2):669-76.
Ready to submit your research? Choose BMC and benefit from:
- fast, convenient online submission
- thorough peer review by experienced researchers in your field
- rapid publication on acceptance
- support for research data, including large and complex data types
- gold Open Access which fosters wider collaboration and increased citations
- maximum visibility for your research: over $100 \mathrm{M}$ website views per year
At BMC, research is always in progress.
Learn more biomedcentral.com/submissions 